\title{
Supranational transfer of digital innovation in agribusiness through payment market mechanisms
}

\author{
Olga Korobeynikova ${ }^{1}$, Dmitry Korobeynikov ${ }^{2,}{ }^{,}$, Larisa Popova $^{2}$, Anna Gorbacheva ${ }^{2}$, and \\ Evgeniy Likholetov ${ }^{2}$ \\ ${ }^{1}$ Volgograd State Technical University, V. I. Lenin Avenue, 28, Volgograd, 400005, Russia \\ ${ }^{2}$ Volgograd State Agricultural University, Universitetsky Avenue, 26, Volgograd, 400002, Russia
}

\begin{abstract}
The task of creating a single supranational payment market is to ensure its maximum independence, which correlates with the tasks of the competitive leading economic development of countries - the transition to a digital technological structure. To increase the efficiency of the generation of payment innovations with their subsequent diffusion into the agricultural sector, to strengthen the economy's resistance to risks, a transfer of innovative institutional, organizational and informational forms of activity is necessary. The strategy of integration of payment markets of interstate economic associations in time and space should be based on the consolidation and symbiosis of innovative technology platforms of sovereign payment systems of the participating countries. For this, a conceptual model of a supranational transfer of digital innovations to the agricultural sector through the transmission mechanisms of payment systems is proposed. The model characterizes the mega-economic system, which provides for the heterarchical and hierarchical interaction of payment systems of donor countries and recipient countries in the framework of economic associations, in which the transfer of forms of innovative development to the agricultural sector is carried out. Digital innovations are transferred to the subjects of the agricultural market horizontally and vertically. The transfer of digital innovation occurs through institutional, organizational and informational communications with the parallel creation of structures for the subsequent evolution of the model.
\end{abstract}

\section{Introduction}

In recent years, the Russian Federation has been under increasing external sanctions pressure, the weakening of which is not projected in the near future. Financial contacts with foreign partners are broken, service by international interbank systems (for example, SWIFT) is compromised. This negatively affects communications in the framework of agricultural markets of countries. Substituting interrupted economic relations, Russia is

\footnotetext{
*Corresponding author: korobeinikov77@yandex.ru
} 
strengthening foreign economic activity in friendly areas in the existing economic unions and associations: The Union State, the CIS, EurAsEC, BRICS, SCO, APEC, etc. Alternative independent interstate payment and settlement channels, data centers, infrastructure elements of payment systems, etc., integrating national payment markets, industry sectors based on unified standardized technology platforms should be created to serve promising economic relations of the common agricultural market.

In these conditions, against the backdrop of the globalization of the economy and in order to increase the efficiency of the generation of payment innovations with their subsequent diffusion into the agricultural sector, as well as to increase the resistance of the economy to risks, it becomes necessary to transfer innovative institutional, organizational and informational forms of activity from leading countries to partner countries in order to:

- expand the scale of attracting a client base and the turnover of participants;

- create and consolidate into a stable trend of the competitive advantages of participating countries and their financial payment institutions;

- form innovative market positions of participants in the agricultural sector;

- accelerate the cash flow of the participating countries and subjects of the payment turnover;

- increase the return on invested innovative capital for both financial participants of the payment market and participants in the agricultural sector.

As previous studies [8] show, the Russian payment market is a growing, customeroriented on an innovative basis, open and multi-subject in terms of quality, it serves economic entities in various fields, including agricultural ones. The mega-task of creating a unified supranational payment market is to ensure its maximum independence from the destructive actions of third parties, which correlates with the tasks of competitive outstripping economic development of countries - the transition to a digital technological structure [7]. Since 2017, a program for the development of the digital economy has been operating in the Russian Federation [5], one of the priority areas of which is agriculture.

Under the conditions of sanctions restrictions, Russian agriculture demonstrates positive development dynamics [6], providing not only the country's food security, but also generating significant export opportunities, which requires appropriate payment and settlement support.

The aim of the study is to substantiate the model of a supranational transfer of digital innovations to agribusiness through transmission mechanisms of the payment market.

The objectives of the study are: 1) conceptual modeling of the supranational transfer of digital innovations to the agricultural sector through the mechanisms of the payment market; 2) the rationale for the heterarchical transfer of digital innovation; 3) the formulation of the directions of the hierarchical transfer of digital innovation.

\section{Materials and methods (model)}

Geo-economic and political challenges that focus on protectionism of domestic economic entities and ensuring food security have intensified applied research, but a holistic industry theory of digital development has not been developed, discussions are underway on the fundamental issues of digitalization of economic sectors, taking into account sectoral characteristics of the agricultural sector [17, 19, 24], improving the elements of the financial mechanism of systems conducting impulses of the digital economy in the agricultural sector $[3,4]$.

Problems of the theory and methodology of the payment market were considered in the works of Russian and foreign experts: Baydukova N.V., Vasilyev S.A., Chepakov D.A. [1], Bech M.L., Preisig C., Soramaki K. [2], Korobov Yu.I., Orlova A.N. [10], Leinonen H., 
Soramaki K. [13], Stiglitz J.E., Bhattacharya A. [22], Travkina E.V., Kovalenko S.B. [23], and others.

Certain aspects of the digitalization of the Russian economy were developed by Kozenko Yu.A. [11], Korobov Yu.I. [9], and others.

However, unified approaches to the innovation of the agricultural sector due to the introduction of digital technologies through the transmission of payment technologies are not presented in the modern specialized literature.

This study is based on general methodological scientific principles (the unity of theory and practice, objectivity, complexity of a concrete historical approach), as well as a systematic approach that involves the formation of a holistic picture of a supranational transfer of digital innovations within the framework of economic associations in agribusiness through transmission mechanisms of the payment market.

\section{Results and discussion}

\subsection{Description of the problem of integration of national and supranational payment markets}

There are fundamental differences between the national and supranational payment markets serving the agricultural sector. National markets are state-regulated and, as a rule, sovereign, which theoretically and practically ensures their ability to function autonomously within national jurisdiction at in-country processing facilities. Payment supranational markets are not sovereign, technologically "tied" to international processing capacities, and therefore vulnerable to external risks of interference that could infect the national markets joining them.

A growing part of the supranational payment market is the online payment market, which serves the online trading sector for agribusiness. It is global by definition and weakly subject to not only state but also supranational regulation. The depth of the problem once again indicates the need to build the integration ties of the payment markets of countries interested in the transparency and reliability of foreign economic relations.

Along with the noted technological aspects of the problem of interstate interaction of economic entities in the payment market, there is also an instrumental aspect - the choice of the payment currency used and the procedure for currency conversion in settlements. In relations between Russia and partner countries, there is a tendency to leave the dollar segment in favor of settlements in national currencies. The instrumental choice should correspond to the nature of the built-in systems of mutual settlements and payments, therefore, the relevance of the choice of national currencies correlates with the independence of the processing of payment transaction processing.

\subsection{Model of a supranational transfer of digital innovation to the agricultural sector through payment market mechanisms}

The strategy of integration of payment markets of interstate economic associations in time and space should be based on the consolidation and symbiosis of innovative technology platforms of sovereign payment systems of the participating countries.

Nowadays, the world community is at the stage of transition to a new technological structure, the generator of which is digital technology. There is an opinion that the country that has most successfully, quickly and widely introduced digital innovations in all areas of the economy will receive global competitive advantages and leadership in the digital world [14]. Following this logic, in the payment sector, it seems advisable to create digital 
systems and transfer forms of innovative development to the agricultural sector [16], where sovereign payment systems will act as an accelerator. Thus, on a digital innovation basis, a competitive advantage of supranational settlement and payment systems for economic entities of the agricultural market will be provided in comparison with similar global forms.

To implement the above provisions, a conceptual model of a supranational transfer of digital innovations to the agricultural sector through the transmission mechanisms of payment systems is proposed. The model characterizes the mega-economic system, which provides for the heterarchical and hierarchical interaction of payment systems of donor countries and recipient countries in the framework of economic associations, in which the transfer of forms of innovative development to the agricultural sector is carried out. Donor countries of digital innovations mean states that have created national systems for generating financial innovations on the basis of testing effective institutional interaction of agricultural market participants. The mechanisms for introducing digital innovations tested by donor countries are borrowed by recipient countries, which accumulate experience and implement best practices in the settlement and payment relations of the agricultural sector based on common standards.

An important characteristic of the model is the transfer of digital innovations from leaders (donors) to partners both horizontally and vertically through institutional, organizational and informational communications with the parallel creation of structures for the subsequent evolution of the model. Horizontal transfers are characterized by heterarchical relations of sovereign structures with overlapping interests regarding correspondent and other coordinated regulated relations. Vertical transfer provides for a flexible hierarchical interaction of structures based on state institutional management and self-regulation of systems.

\subsection{Heterarchical transfer of digital innovation}

The heterarchy of economic systems of the agrarian market of the same order should affect at least the following aspects.

1. Domestic and cross-border payment spaces - include national and supranational agricultural markets, payment infrastructure, payment services, payment transaction entities united by a single digital environment.

2. Technological platforms being introduced into domestic and cross-border payment spaces are a combination of forms, methods, techniques and tools of intra-sphere generation and inter-sphere diffusion of innovations. Technological platforms are the basis of heterarchical relations of innovative interaction. The combination of technology platforms forms a digital ecosystem of intercountry economic unions and associations.

3. Projects of a heterarchical transfer of digital innovations should be implemented in the inter-sphere fields at the intersections of sciences and innovative technologies. The results of the projects in this case will be a fundamentally new settlement and payment products serving the agricultural sector. Among the projects that provide not only a direct, but also an indirect effect projected onto adjacent areas, there may be: the creation of a single economic, digital and social space [18] based on a new technological structure; the practical achievement of direct currency conversion within the framework of supranational partner associations and free cross-country settlements; possible joint issue and circulation of a supranational cryptocurrency secured by non-virtual tangible and intangible assets of issuers, etc.

4. Transfer processes of digital innovations in the horizontal plane of national payment institutions, entities of the agricultural market. The heterarchical transfer of innovations is carried out in the unity of opposites - competition and cooperation processes [12], 
coordination and integration, which seems necessary and possible to achieve the mega-task of creating a single payment space.

Cooperation processes in the transfer of digital payment innovations to the agricultural sector consist in the joint activities of the payment market entities in the development of software, payment services, payment products, the sharing of information transfer channels, due to which (in accordance with the classical principles of cooperation), the effect of acceleration of the results is achieved. Heterogeneous cooperative relations characterize the symbiosis of financial and non-financial participants and are distinguished by the convergence of nano-, bio-, information, cognitive technologies and the corresponding inter-sphere participation of entities of the financial, IT, communication, agricultural and other sectors.

Coordination processes at the horizontal level involve joint processes of regulation (mainly) and self-regulation (to a lesser extent) by payment market entities of areas of overlapping interests and relations in a single payment space in accordance with supranational rules and standards [21].

Integration processes in the horizontal plane should be implemented both in organizational forms of supranational unions and similar structures, and in the form of consortia and other associations without the formation of legal entities at the levels of interindustry, inter-sphere, inter-company, inter-subject and other relations. Horizontal cooperation in this case will provide synergy, a greater socio-economic effect than vertical, due to the initiative motivation of participants at each level, flexible operational choice of products and transfer mechanisms [20].

5. Digital products of new generations with a high share of intellectual surplus value. First of all, such payment products are digital payment services, for the successful transfer of which on a permanent basis it is important to ensure transparency of the payment space, comparability of supranational and national regulation and standardization. Heterachical contacts regarding the transfer of digital innovations to the agrarian sphere also imply a certain universality of payment identification tools, which consists in the following. Traditional payment instruments should be used to the extent that they support the geoeconomic security of the created integration system; payment card products of national payment card systems may claim this role. Innovative non-card tools can ensure geoeconomic sovereignty and security (with certain assumptions regarding the industry standards and Internet communication networks) if the methods and mechanisms for transmitting transaction data are unified and standardized. To obtain a digital product of heterarchical interaction, the problem of the intra-system transfer protection of information about transactions and technologies for their implementation on the unified standards of protecting information from unauthorized interference and criminal use should also be solved. Thus, as a result of a combination of spaces, platforms, projects and processes, digital payment products are created on a supranational plane, which, in turn, can serve as a transmission mechanism for transferring digital innovations to participants in the agricultural market.

\subsection{Hierarchical transfer of digital innovation}

Unlike the first direction (heterarchical transfer), which is not directly controlled by the process, mainly driven by market forces, the hierarchical transfer can and should be managed centrally by the supranational bodies of digital development and coordinated with the geopolitical strategy of breakthrough development, protection of sovereign interests and food security.

Three directions of transfer of digital innovations to the subjects of the payment market are proposed: integration; clustering collaboration. 
1. For the formation of a single payment market, phased integration of all forms and types of payment systems is advisable: by institutions, methods, processes, and products.

In the Russian Federation, payment systems, as the main system-forming participants in the payment market, are successfully operating. They prove the effectiveness and competitiveness in servicing the individual financial and social needs of the economy and society. But despite the demand for payment system services in the national aspect, there is no doubt the relevance of the formation of an interstate payment and settlement space. It is known that the operational and (or) territorial localization of the activity of payment systems is a factor in limiting the steady progressive growth of not only quantitative indicators, but also the quality of the services provided both by the actual payment systems and the payment sector of states [15]. However, the creation of an interstate payment market and its supranational entities should not automatically deactivate the demand for services of national entities of payment systems. On the one hand, the creation of a common payment infrastructure and architecture will positively affect the efficiency of all participants: government agencies, business entities, and the population. On the other hand, due to excessive universalization, erosion of the competitive advantages of national participants related to the adaptation of services to the mentality and requests of a specific user may occur. To avoid the loss of accumulated positive experience, it is important to integrate payment systems organically, taking into account individual requests. What is needed is not the absorption of payment systems, but their "subtle integration" into the infrastructure of a supranational payment market, taking into account the specifics of the occupied segment.

1.1. Integration by institutions with the creation of common governing bodies, the creation or adaptation of common payment networks (based on the created alternative analogue of the SWIFT system of group jurisdiction of the European Union and/or the improvement of sovereign networks and/or the formation of new networks based on blockchain technologies), clearing networks, the formation of common data processing centers with the preservation of their sovereignty in terms of information protection, which together will form the institutional environment for the accelerative transfer of payment innovations to the agricultural sector and other areas.

The most acute here is the problem of creating or adapting payment networks for crossborder operations. Recently, the Russian Federation has repeatedly faced the threat of disconnecting from the international payment system SWIFT, the answer to which may be the development of alternative methods of transmitting payment information. For example, the most likely analogue option is the payment network created by the countries of the European Union - Blockchain World Wire. This is a global payment blockchain system based on the Stellar protocol, with the help of which banks will be able to make international payments using clearing. Developers guarantee instant (several seconds to confirm operations) speed of payments between participants in the system. Within the framework of the system, it is planned to conduct transactions with both fiat money and cryptocurrencies, as well as between them, which creates opportunities for the issue of supranational cryptocurrencies (at least for mutual cross-border settlements). Blockchain World Wire payment network can become a full-fledged competitor not only for SWIFT, but also for Ripple's xRapid Ripple project (which positions itself on the interbank market as an innovative leader bringing financial markets and tokens together).

1.2. Integration by methods of supranational regulation, standardization, supervision and control.

When integrating payment systems for a supranational transfer of digital innovation in the agricultural sector, it is advisable to build an external impact policy, including regulation and incentives. When organizing such an impact at the stages of formation and functioning of an integrated system, an individual approach to the subjects of the selected 
groups is required, regardless of the degree of centralized certainty and conditionality of the elements, their coordination from the side of the central element.

Regulation and self-regulation presuppose a high level of standardization of payment system operations, aimed at increasing the degree of conformity of products and technological processes to their functional purpose for servicing participants in the agricultural market, and eliminating artificial technical barriers to entry of participants.

When realizing the task of a supranational transfer of digital innovations to the agricultural sector, it seems important to introduce standardization procedures at least for the key parameters of innovation transfer:

- ensuring the security of processing, transmission and storage of data;

- conducting settlement procedures between participants in the system and individual payment systems;

- compliance with time regulations and processing speed of various types of transactions in payment systems;

- basic requirements for the functionality of payment instruments;

- basic identification parameters of various categories of users, etc.

1.3. Integration through multi-level cooperation and market coordination processes.

1.4. Integration through products of vertical integration in the form of supranational operational standards, information protection and crime prevention standards, common digital competencies in scientific research, the educational environment, special (financial) and general (nano, bio, information and cognitive) technologies.

2. Clustering of payment systems and payment market entities serving the agricultural sector.

As a result of vertical integration, clustering of payment systems and payment market entities should take place, which provides for the consolidation and merger of payment systems with the formation of new organizational structures - payment clusters, as well as a symbiosis of financial and non-financial technologies in the agricultural sector. Clustering should occur on an operational basis, but also within the framework of operational clusters, territorial clusters can also be formed that carry out a local transfer of digital technologies to agricultural entities.

To form cluster groups, the prerequisites of an economic and regulatory nature should be created:

- ensuring the unity of the legislative regulatory and normative field manifested in the creation of a successive vertical of laws, regulations, instructive documentation;

- protectionism of national payment systems on the one hand, and protective measures against the national agricultural market on the other hand;

- creating transparent conditions for entry and mechanisms for the functioning of associations, which include: unification of the rules of participation, requirements for participants; unambiguous understanding of the rights, duties and responsibilities of participants; formalization of relations between participants, etc.;

- ensuring the technical attractiveness or at least the acceptability of the technical and technological aspects of integration into the group, which means competitive preference for various forms of cooperation in the payment cluster with the availability and ease of adaptation of technical support for the functioning of the subject as an independent unit and as an element of the cluster;

- development of a common infrastructure for the territorial expansion of payment systems with equalization of the levels of regional provision with high-tech and highperformance means of information transfer. If various software, hardware and technology platforms are used, then there will be no guarantees for the implementation of transactions by different entities of payment systems;

- the provision of new economic incentives for newcomers, including: 
a) tax preferences for the initial stage of functioning of the cluster element in the form of investment tax credits, etc.;

b) general subsidiary funding replacing individual funding of cash on accounts in national structures, allowing individual participants to achieve savings in funding sources and their redistribution to operational activities;

c) general subsidiary mandatory and voluntary reservation of liabilities by the payment system, replacing individual reservation by participants;

d) creation of self-insurance funds to minimize newly arising and previously present financial and other risks that are actualized in connection with the innovation of the payment market;

e) preferential domestic lending for temporary gaps in the payment turnover of financial participants and non-financial agricultural participants within a cluster with lower requirements for collateral and opening credit lines with a predetermined limit, which will contribute to a rational flow of capital that regulates current cash flows;

f) cluster pricing mechanisms consisting in the possibility of differentiating the cost of services for cluster members, setting preferential domestic tariffs.

- outreach and awareness-raising work and educational activities of states and economic entities to improve the financial and communication literacy of users of payment systems, individually oriented to different age groups of the population, certain groups of legal entities - users of payment systems. The activity should be aimed at advertising the benefits of using national and supranational payment systems, training in the technologies and practice of using payment instruments and payment equipment, mastering the methods of protecting one's own information, personal data and money, etc.

3. Collaboration of payment systems and payment market entities related to the agricultural sector.

Collaboration is considered as a new, evolving form of cooperation in the innovative knowledge economy and is characterized by the common goals of the participants in creating a single digital space of the digital economy. It is proposed to apply collaboration in the transfer of digital innovations through the mechanisms of payment systems in relation to agribusiness, sectors and segments of supranational interaction, according to hierarchy levels and scales, by subjects and objects of the payment market.

The financial science and practice of foreign countries considered various options for collaboration mechanisms of payment systems, which are based on the criterion of state participation in the formation and subsequent management of systems. According to the degree of state participation and its role in determining strategies and managerial mechanisms for their implementation, three main types of models for organizing collaborative relationships of payment systems are distinguished: a market-regulated (free) model, a public-private model (public-private partnership), and a public corporation model.

The free model is based solely on private initiative and does not provide for direct active participation (only indirect regulation and supervision) on the part of the state in the development of payment services, mass payment methods, and the use of payment instruments in the economic and social spheres. The absence of direct budgeting, a high degree of market freedom and a sufficient level of competition make this model attractive from the point of view of traditional ideas about the mechanisms of a market economy. However, there are also limiting factors of the free model in the application of high risks and uncertainties in the modern economic environment: the impossibility of direct implementation of state policy and national projects, insufficient coverage of broad segments of the population, concentration of resources only on market sectors that are profitable in business terms, etc.

The collaboration of payment systems with the creation of state corporations in the participating countries is also considered as a possible development model that provides the 
most complete consideration of the interests of states and society as a whole. The status of state corporations in this case should be non-profit, implying the direction of profits in the framework of entrepreneurial activity to achieve the goals of its creation. Given the unconditional social and structural significance, the task of creating state-owned corporations has limitations associated primarily with the enormous direct costs of creating a unified technological platform. In addition, the experience of countries that have taken the path of creating state-owned decentralized payment systems shows that the pace of development of state structures is lower than the market average, approaches to taking into account local characteristics are not flexible, the services provided are less high-quality and less in demand compared to commercial competitors.

As a compromise option, taking into account the advantages and disadvantages of previous models, public-private partnerships are considered.

In this approach to the formation of a model of a supranational transfer of digital innovation in the agricultural sector, it is unacceptable that the process of its implementation be considered exclusively as an administrative and regulatory, hierarchical action. Participants of national and supranational payment systems and agricultural entities are guided by the development of their business in conditions of equal market competition. It involves the participation of a commercial initiative, attracting private investment through the use of various forms of collaboration: formal and informal private partnerships, as well as public-private partnerships in those segments where it is impossible to use exclusively private resources (for example, logistics distribution centers for agricultural products, etc.).

The proposed model does not contain indications of mandatory institutional elements: banks and non-banking financial organizations, but characterizes only multilevel relations regarding the formation and functioning of a single payment space based on common standards and technologies for servicing agricultural and other market entities. We expect that in the future, traditional financial (payment and settlement) intermediaries will be replaced by other forms of mediation, or the mediation institution will be liquidated due to the technological replacement of its functions (blockchain technology, open interfaces, etc.). Therefore, it is necessary to talk about the parallel creation of structures of the subsequent evolution of the model and mechanisms of operative point interference in processes by influencing not only hierarchical relationships and elements (which seems directly feasible through legal provisions), but also controlled stimulation of the evolution of heterarchical relations.

\section{Conclusion}

The strategy of integration of payment markets of interstate economic associations in time and space should be based on the consolidation and symbiosis of innovative technology platforms. It is necessary to transfer digital innovations from leaders (donors) to partners horizontally (in-country and cross-border payment spaces, technological platforms of national payment systems, projects of a single economic, digital and social space based on a new technological structure, innovation transfer processes in the horizontal plane of national payment systems, digital products of new generations with a high share of intellectual surplus value), and vertical (integration, clustering, collaboration), with the creation of a parallel structure of future evolution of the model.

The proposed model corresponds to the accelerated development of a new digital technological structure in the agricultural sector, takes into account transformational relationships on a global scale, and mobilizes all the links of the system under consideration. It provides the following for participating countries and agribusiness entities: 
- intensive implementation (or acceleration of extensive development) of a new digital technological structure;

- improving the investment climate, stability and security of the common market;

- expansion of the capacity of domestic markets due to the common market, complementarity of markets;

- increase in demand for digital payment and other financial services and instruments (non-fiat currencies, provided that they are controlled by the state) while reducing the cost of these services due to global effects of the scale of the resource and customer base;

- competition and high efficiency of entities based on progressive market positions;

- acceleration of money turnover and growth of return on invested money capital in the agricultural sector;

- other private economic, political and social effects.

\section{References}

1. N. Baydukova, S. Vasilyev, D. Chepakov, Bulletin of Saint-Petersburg State University, 1,17-26 (2016)

2. M. Bech, C. Preisig, K. Soramaki, FRBNY Economic Policy Peview (2008)

3. D. Burkaltseva, O. Sivash, O. Boychenko, et al., European Research Studies Journal, 10, 4B, 366-379 (2017)

4. D. Burkaltseva, O. Boychenko, O. Sivash, et al., European Research Studies Journal, 10, 4B, 350-365 (2017)

5. http://static.government.ru/media/files/9gFM4FHj4PsB79I5v7yLVuPgu4bvR7M0.pdf

6. T. Dugina, E. Likholetov, A. Nemchenko, et al., Biosciences Biotechnology Research Asia, 12, 1, 549-555 (2015)

7. Forecast long-term socio-economic development of the Russian Federation for the period up to $2030 \mathrm{http}$ // base.garant.ru/70309010/\#friends

8. O. Korobeynikova, D. Korobeynikov, Proceedings of Nizhnevolzhsk Agrouniversity Complex: Science and Higher Vocational Education, 2, 38, 246-251 (2015)

9. Yu. Korobov, Science and Society, 3, 22, 39-41(2015)

10. Yu. Korobov, A. Orlova, Finance, Money, Investment, 3, 7-11 (2010)

11. Yu. Kozenko, Business, Education. Right. Bulletin of the Volgograd Business Institute, 4, 184-188 (2013)

12. Y. Kozenko, Z. Kozenko, A. Bobicheva, et al., European Research Studies Journal, 19, 2, 171-178 (2016)

13. H. Leinonen, K. Soramaki, Bank of Finland Discussion Papers, 16, 1-55 (1999)

14. R. Levine, N. Loayza, T. Beck, Journal of Monetary Economics, 46, 1, 31-77 (2000)

15. R. Nelson, E. Phelps, American Economic Review, 56, 2, 69-75 (1996)

16. A. Nemchenko, T. Dugina, E. Likholetov, et al., International Journal of Economics and Financial Issues, 6, S2, 207-211 (2016)

17. L. Popova, D. Korobeynikov, et al., Journal of Applied Economic Sciences, 11, 6, 44, 1034-1044 (2016)

18. A. Razin, T. Nazarova, Proceedings of Nizhnevolzhsk Agrouniversity Complex: Science and Higher Vocational Education, 2, 42, 302-307 (2016)

19. O. Semenyuta, N. Panchenko, Finance and Credit, 41, 569, 2-7 (2013)

20. R. Shepitko, I. Koshkarev, Proceedings of Nizhnevolzhsk Agrouniversity Complex: 
Science and Higher Vocational Education, 1, 25, 201-206 (2012)

21. R. Skokov, Modern Economy: Problems and Solutions, 5, 41, 13-20 (2013)

22. J. Stiglitz, A. Bhattacharya, Underpinnings for Stable and Equitable Global Financial System, World Bank, New York (1999)

23. E. Travkina, S. Kovalenko, Collection of articles of International Scientific-Practical Conference, 139-141, Aeterna, Ufa (2016)

24. N. Zavivaev, E. Shamin, Proceedings of Nizhnevolzhsk Agrouniversity Complex: Science and Higher Vocational Education, 4, 40, 233-239 (2015) 